\title{
DIMENSÕES SÓCIOECONÔMICAS E MOVIMENTOS POPULACIONAIS: UMA REGIONALIZAÇÃO DA AMAZÔNIA BRASILEIRA
}

\author{
Ricardo Alexandrino Garcia* \\ Britaldo Silveira Soares \\ Diana Oya Sawyer
}

\section{Resumo}

A dinâmica socioeconômica brasileira vem causando profundas mudanças ambientais na Amazônia através do rápido desflorestamento deste vasto bioma, com a consequente perda de seus serviços ecológicos, como a depleção nos repositórios de biodiversidade e alteração no clima global. Medidas de planejamento de uso e conservação dos recursos naturais devem analisar essa dinâmica socioeconômica e seu potencial de impacto ambiental à luz de uma configuração territorial. Por outro lado, a configuração socioeconômica da Amazônia brasileira tem diferenciadas implicações sobre sua dinâmica ambiental e, consequentemente, sobre a adequação de políticas de desenvolvimento sustentável. A definição de uma regionalização, que traduza configuração da rede socioeconômica dos municípios, é o ponto de partida para a caracterização da diversidade de processos envolvidos na ocupação desse território. Foi desenvolvido, nesse sentido, um índice sintético que refletisse o grau de desenvolvimento social e econômico dos municípios da Amazônia com base em dados de Censos Demográfico e Agrícola. O método de classificação nebulosa GOM foi utilizado para gerar 5 dimensões, a saber: 1) concentração e dinâmica demográfica, 2) desenvolvimento econômico, 3) infraestrutura agrária, 4) atividade agropecuária e extração vegetal e 5) Desenvolvimento social, cuja a combinação resultou em um índice de Desenvolvimento socioeconômico. Feito isso, foi elaborado um modelo gravitacional de regionalização - baseado nesses índices e na a dinâmica migratória da região - que possibilitou a análise da rede de municípios da Amazônia brasileira.

Palavras-Chave:desenvolvimento socioeconômico, migração, regionalização, Amazônia.

*Do Cedeplar/UFMG.

'Do IGC/CRS/UFMG.

-Da Face/Cedeplar/UFMG.

Cadernos do Leste

Artigos Cientificos

Belo Horizonte, Jan.-Dez. Vol.9, n 92009 


\section{1- INTRODUÇÃO}

A dinâmica socioeconômica brasileira vem causando profundas mudanças ambientais na Amazônia através do rápido desflorestamento deste vasto bioma, com a consequente perda de seus serviços ecológicos (Fearnside, 1997). Logo, estudos de planejamento de uso e conservação dos recursos naturais devem analisar essa dinâmica socioeconômica regional para fins de avaliação do seu potencial de impacto ambiental.

Dentre os indicadores de pressão de impacto ambiental, o índice de pressão antrópica, como proposto por Monteiro e Sawyer (2001), representa um indicador de pressões econômicas e demográficas sobre o meio ambiente. Segundo estes autores, o índice de pressão antrópica, construído sobre uma base de dados secundários, sintetiza as pressões de transformação que um determinado meio-ambiente está sujeito devido à ação humana, quer seja no tocante à poluição ou depleção dos recursos naturais. Nesse sentido, pressão antrópica diferencia-se de impacto ambiental, pois o primeiro implica em potencial de transformação, enquanto o segundo especifica as consequências ambientais. Em outras palavras, o índice de pressão antrópica consiste em indicador útil para se avaliar o potencial de dinâmica ambiental de uma determinada região diante de um conjunto de condições socioeconômicas de contorno.

A dinâmica social, econômica e ambiental no espaço pode, por outro lado, exercer forte determinação sobre a reconfiguração urbana da Amazônia brasileira. Esta, por sua vez, tem implicações diferenciadas sobre aspectos sociais e econômicos e, consequentemente, sobre a adequação de políticas de desenvolvimento sustentável.

Para isso, torna-se necessário a definição de uma regionalização que traduza a configuração da rede socioeconômica de cidades do território amazônico e que se busque critérios que possibilite a hierarquização dos pólos socioambientais da Amazônia brasileira e suas áreas de influência.

No plano teórico, a regionalização fundamenta-se no reconhecimento de que a distribuição desigual da população urbana no espaço advém da eficiência social e econômica, cujo substrato mais palpável são as economias externas de escala provenientes da concentração urbana e da oferta de serviços especializados que, por sua vez, retroalimentam o sistema de relações sociais, modificando sua estrutura, ao longo do tempo.

Configura-se, assim, uma hierarquia nodal urbana formada pelo centro de maior tamanho e por centros menores em seu entorno, os quais possuem ofertam serviços diferenciados, bem como apresentam diferenciados perfis sociais. A teoria do lugar central (PERROUX, 1957), vista sob esse aspecto, enseja claramente uma concepção de área de mercado a ser polarizada pelo Cadernos do Leste 
centro urbano de maior população e densidade na oferta de serviços e, consequentemente, de maior potencial econômico.

Por essa razão, o peso do produto interno bruto do terciário sobre o produto interno bruto total de uma localidade (Índice de terceirização) é o melhor indicador de sua capacidade de polarização de outras localidades. Essa relação traduz, por um lado, a capacidade de alocação do conjunto dos aspectos sociais, econômicos e ambientais, apresentados por uma dada localidade, num determinado período e, por outro, revela, também, a capacidade de disseminação dessas características para seus vizinhos, indicando em que medida que esses aspectos terão influência sobre outras localidades (LEMOS, 1991).

Nesse sentido, a rede de localidades economicamente estruturada da Amazônia brasileira será dada pelos conjuntos de cidades influenciados por estes lugares centrais. Ao adquirir um determinado porte, no entanto, um lugar de maior densidade urbana tende a se constituir em um centro de produção e consumo coletivo e a atrair um fluxo de pessoas se deslocando até ele, em busca de atividades especializadas. Os deslocamentos humanos no espaço e no tempo desempenham, portanto, um papel crucial na configuração das redes sociais das cidades da Amazônia brasileira.

Para efeitos operacionais, o critério de regionalização, aqui empregado, visa estabelecer o recorte do território amazônico em macro, meso e microrregiões. Constituir-se-á uma macrorregião (MACRO) a parcela do território polarizada por uma grande concentração urbana com características de metrópole (macropolo). Por sua vez, cada macrorregião é dividida em mesorregiões (MESO), segundo a capacidade secundária de polarização exercida por grandes ou médias cidades (mesopolo). Finalmente, cada mesorregião está subdividida em microrregiões (MICRO).

Sob essa luz, este trabalho busca desenvolver um índice sintético que possa ser indicador do potencial de desflorestamento nos municípios da Amazônia Legal brasileira. Para tanto são usados insumos sociais e econômicos, derivados de censos demográfico e agropecuário, para se gerar uma hierarquia de municípios.

Este trabalho é, portanto, um esforço de se buscar a caracterização da rede de cidades que estruturam o espaço socioeconômico da Amazônia brasileira, através de um modelo gravitacional regionalização que articula tanto os níveis de desenvolvimento socioeconômico dessas localidades, quanto o grau de suas inter-relações, dado pelos movimentos populacionais entre elas. Como isso, pretende-se avaliar a pressão de algumas dimensões da atividade humana e sua a 
implicação na configuração territorial da dinâmica espaço-temporal do processo do desflorestamento amazônico.

\section{O índice de Desenvolvimento Socioeconômico}

O índice de Desenvolvimento socioeconômico (IDSE) é calculado com base na exploração de várias fontes de dados disponíveis, as quais trazem uma gama considerável de informações sociais e econômicas desagregáveis até o nível municipal e, em certos casos, intramunicipal, a saber: censos demográfico de 1991 e 2000 e agropecuário de 1995/1996 (IBGE, 1996; 1996a; 2000), estimativas de produto interno bruto de municípios (Andrade \& Serra, 1999), dados de exploração e produção madeireira (Veríssimo et al., 2001), banco municipal de informações (IBGE, 1998) e perfil dos municípios brasileiros (IBGE, 1999).

Se o que se está objetivando é a construção de um indicador de pressão antrópica e este conceito parte de distintas dimensões é natural, por conseguinte, que se construam também indicadores representativos de cada uma dessas dimensões, a partir da combinação das variáveis passiveis de mensuração empírica. Portanto, o Índice de Desenvolvimento Social foi decomposto em cinco dimensões básicas dadas pela Concentração e Dinâmica Demográfica, pelo Desenvolvimento Econômico, pela Infraestrutura agrária, pela Pressão das Atividades Agropecuária e de Extração Madeireira e pelo Desenvolvimento Social. Cada uma dessas cinco dimensões agrega um delimitado conjunto de variáveis que se combinam em um índice específico dessa dimensão para cada município. Por fim, a combinação de todos os cinco índices dimensionais conforma o índice de Desenvolvimento socioeconômico.

Para elaboração destes índices foi empregado o método GoM - Grade of Membership (Zadeh, 1965; Manton et ali, 1994), técnica que tem sido empregada em uma variedade de estudos para a definição de perfis multivariados (Sawyer \& Beltrão, 1991; Garcia 2000; 2000a). A técnica GoM estima, com base em um modelo de probabilidade multinomial, dois tipos de parâmetros: um de associação, gik, e outro de estrutura, lkjl , ou seja, os graus de pertinência $(\mathrm{g})$ de cada elemento (i) a cada subconjunto, ou perfil, ou tipo (k); e as probabilidades de cada categoria (l) de cada variável (j) em cada perfil (k) que, por sua vez, define esse perfil (eq. 1).

\section{Equação 1: FUNÇÃO DE MAXIMA VEROSSIMELHANÇA DO MODELO GoM.}

$$
L_{(y)}=\prod_{i=1}^{I} \prod_{i=1}^{J} \prod_{i=1}^{L j}\left(\Sigma g_{i k} \lambda_{k j l}\right)^{Y i j l}
$$

Esse modelo permite que se estime tanto as probabilidades de cada categoria das variáveis internas ao modelo de participar da composição dos perfis puros, quanto o grau de pertinência de 
cada elemento imputado a esses perfis. Como trata-se da construção de índices sintéticos, a partir de variáveis cujas probabilidades das categorias que compõem os perfis desejados é conhecida à priori, não foi necessário que o modelo estimasse os lkjl, mas, apenas os gik para somente dois perfis. Dessa forma, os gik estimados estavam condicionados a um conjunto de lkjl previamente estabelecidos para cada categoria das variáveis em cada um dos dois perfis, de tal forma que os perfis puros obtidos fossem exatamente os extremos de um contínuo de cada dimensão.

Para esse procedimento, todas as variáveis foram categorizadas em cinco grupos, de acordo com seus quintis. Os municípios puderam, assim, ser classificados em uma escala de 1 a 5 em cada uma das 29 variáveis de estudo. $O$ valor 1 representou o substrato inferior e o 5 o substrato superior de cada variável. Para que um município obtivesse o grau de pertinência máximo, ou seja, 100\%, ao primeiro tipo puro da dimensão Concentração e Dinâmica Demográfica, era necessário que o mesmo pertencesse ao substrato superior de cada uma das variáveis que compuseram essa dimensão.

O construto apresentado na TAB. 1 indica como foi esquematizada a seleção das variáveis componentes do Índice de Desenvolvimento Social dos municípios da Amazôniabrasileira. Nele, estão representadas as dimensões e os seus aspectos que podem ser investigados empiricamente por meio de bases públicas de dados. 


\title{
VARIÁVEIS COMPONENTES DAS CINCO DIMENSÕES DO ÍNDICE DE DESENVOLVIMENTO SÓCIOECONÔMICO
}

\author{
ICDD: Índice de Concentração e Dinâmica Demográfica \\ População Total (2000) ${ }^{1}$ \\ Densidade Demográfica (2000) ${ }^{1}$ \\ Grau de Urbanização $(2000)^{1}$ \\ Taxa Anual de Crescimento (1996/2000) ${ }^{102}$
}

IDE: Índice de Desenvolvimento Econômico

Produto Interno Bruto (1996) ${ }^{6}$ (Andrade e Serra, 1996)

Produto Interno Bruto: setor primário (1996) ${ }^{6}$

Produto Interno Bruto: setor secundáro (1996) ${ }^{6}$

Produto Interno Bruto: setor terciário (1996) ${ }^{5}$

Número de Agências Bancárias (1998) ${ }^{3}$

Valor dos depósitos Bancários - em mil reais (1998) ${ }^{3}$

Valor das Aplicações - em mil reais (1998) ${ }^{3}$

Receitas orçamentárias realizadas $(1997)^{3}$

Despesas orçamentárias realizadas $(1997)^{3}$

Valor do Fundo de Participação dos Municípios (1998) $^{3}$

Valor do Imposto Territorial Rural - (1998) ${ }^{3}$

IIA: Índice de Infra-estrutura agrária Valor da produção animal e vegetal (1995-1996) " Total de Tratores (1995-1996) ${ }^{\circ}$

Total Máquinas de plantio (1995-1996) ${ }^{\circ}$

Total de colheitadeiras (1995-1996) ${ }^{\circ}$

Total de Caminhöes (1995-1996) ${ }^{\circ}$

Total de Utilitários (1995-1996) ${ }^{\circ}$ 


\title{
VARIÁVEIS COMPONENTES DAS CINCO DIMENSÕES DO ÍNDICE DE DESENVOLVIMENTO SÓCIOECONÔMICO
}

\author{
IAAEM: Índice de Atividade Agropecuária e de Extração Madereira \\ Área total dos estabelecimentos agropecuários com área inferior a 200 Há. (1995-1996) ${ }^{\circ}$ \\ Área total dos estabelecimentos agropecuários com área superior a 200 Há. (1995-1996) ${ }^{\circledR}$ \\ Índice de concentração fundiária (1995-1996) ${ }^{\circ}$ \\ Efetivo do Rebanho (2000) ${ }^{\text {7a }}$ \\ Taxa anual de crescimento do Efetivo do Rebanho $(1997-2000)^{7 a} \circ 70$ \\ Densidade das lavouras (2000) ${ }^{\mathrm{aa}}$ \\ Taxa anual de crescimento das lavouras entre $(1997-2000)^{\text {aa e so }}$ \\ Número de industria madeireiras $(1997)^{\circ}$ \\ Estração de Madeira em tora por ano (1997) \\ Área Afetada (1997) ${ }^{\circ}$
}

IDS: Índice de Desenvolvimento Social

Educação

Anos de estudo - \% pessoas residentes - 7 a 14 anos de idade - média (1996) ${ }^{2}$

Anos de estudo - $\%$ pessoas residentes - 15 a 24 anos de idade - média $(1996)^{2}$

Anos de estudo - \% Chefes de Domicílios - média (1996) ${ }^{2}$

Saúde
Hospitais
Leitos hospitalares (por 1000 habitantes) ${ }^{3}$
Unidades ambulatoriais (por 1000 habitantes) ${ }^{3}$
Postos de saúde (por 1000 habitantes) ${ }^{3}$
Centros de saúde (por 1000 habitantes) ${ }^{3}$
Ambulatórios de unidade hospitalar geral (por 1000 habitantes)
Postos de assistência médica (por 1000 habitantes) ${ }^{3}$
Internações hospitalares (por 1000 habitantes) ${ }^{3}$

Habitação e Saneamento

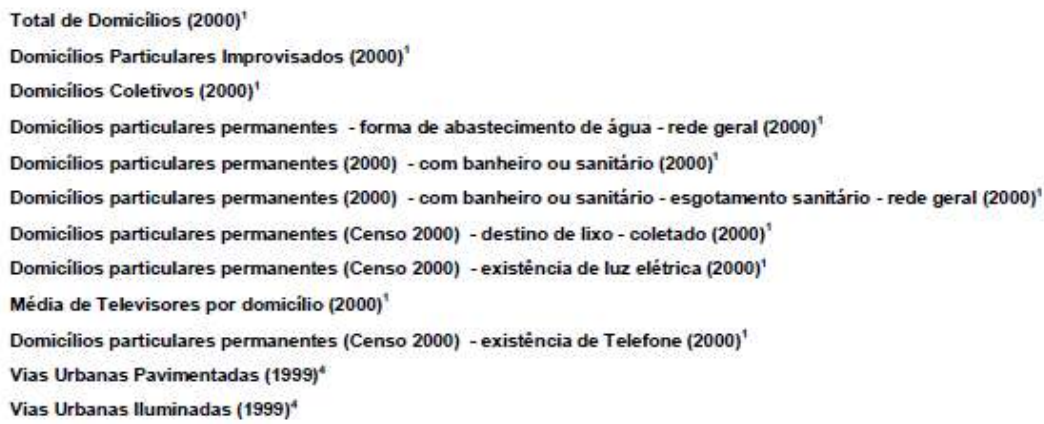

Fonte: 1) IBGE. Censo Demográfico 2000; 2) IBGE. Contagem de 1996; 3) IBGE. Banco de Informaçòes Municipais, 2² Ed. 1999; 4) Perfil dos Municipios Brasileiros, $1^{2}$ Ed. 1999; 5) ANDRADE E SERRA, 1996; O) IBGE. Censo Agropecuário 1995-1996; 7a) IBGE. Pesquisa Pecuária Municipal de 2000; 7b) IBGE. Pesquisa Pecuária Municipal de 1997; 8a) IBGE. Pesquisa Agricola Municipal de 2000; 8b) IBGE. Pesquisa 


\section{A hierarquia urbana}

A base da regionalização aqui proposta foi, primeiramente, a construção de um índice de terceirização (IT), calculado com base na relação entre o PIB do setor terciário e o PIB total, como já mencionado. O cálculo de IT para todas as áreas de mercado de um macro espaço econômico possibilita o estabelecimento de uma hierarquia inter-regional baseada na densidade urbana destas áreas, dada pela dupla capacidade de "carregamento" e "transbordamento" de seus serviços (LEMOS et al., 2000. p 09). Esse índice de terceirização pode ser representado de acordo com a seguinte expressão:

$$
\begin{gathered}
\text { Equação 2: } \\
\text { INDICE DE TERCIARIZAÇÃO } \\
I t_{I}=\frac{P I B(\text { ter })}{P I B(t o t)},
\end{gathered}
$$

Na qual: It $\mathbf{t}_{\mathbf{i}}$ é o índice de terciarização da localidade i; PIB(ter )é o produto interno bruto do setor terciário de i e PIB(tot) é o produto interno bruto total de i.

Para que se evite distorções desse índice, em localidade cuja densidade econômica é muito baixa, como é o caso de certos municípios amazônicos,lançar-se-á mão de um conversor logarítmico de escala, que atribuía o maior PIB, denominado PIB referencial, o fator 0,95. O cálculo para as demais áreas considera a proporção logarítmica inversa, representada pela expressão abaixo:

$$
\begin{gathered}
\text { Equação 3: } \\
\text { PRODUTO INTERNO BRUTO TOTAL CONVERTIDO } \\
P I B t_{c i}=1-e\left(\frac{\ln (0.05)}{P I B t_{\text {ref }}}{ }^{*} P I B t_{i}\right)
\end{gathered}
$$

na qual: PIBtci é o produto interno bruto convertido da localidade i; PIBti é o produto interno bruto de i e PIBtref é o produto interno bruto de referência.

Uma vez calculado o PIB total convertida, pode-se ajustar o Índice de Terceirização, efetuando-se o seguinte cálculo:

$$
\begin{aligned}
& \text { Equação 4: INDICE DE TERCIARIZAÇÃo AJUSTAdo } \\
& \qquad I t_{I^{*}}=I t^{*} P I B t_{c}
\end{aligned}
$$

na qual: Iti* é o índice de terceirização ajustado da localidade i; : Iti é o índice de terceirização 
de i e PIBtc é o produto interno bruto total convertido de i.

\section{O modelo gravitacional de regionalização socioeconômica}

$\mathrm{Na}$ elaboração de uma regionalização socioeconômica dos municípios da Amazônia brasileira, será empregado um modelo inspirado no modelo gravitacional proposto por ISARD (1975). Uma vez estabelecida a hierarquia dos centros urbanos amazônicos, serão calculados os Índices de Interação entre esses centros e as demais localidades geográficas. O cálculo dos Índices de Interação pode ser expresso da pela seguinte equação:

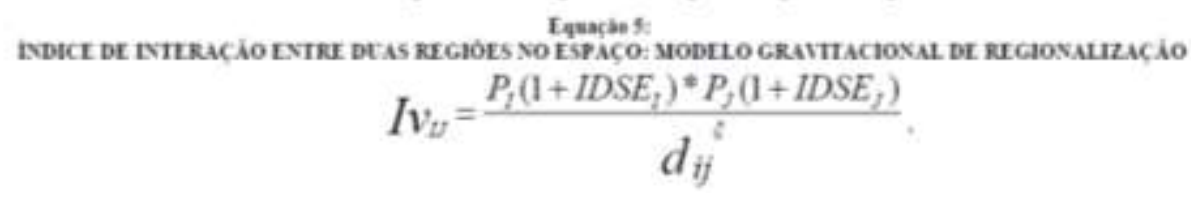

na qual: Ivij representa o índice de interação gravitacional entre a região i e região j; Pi e Pj são as respectivas populações das regiões i e j; IDSEi e IDSEj representam os índices de desenvolvimento socioeconômico das regiões i e j, respectivamente; dij é distância geodésica ortodrômica entre elas e $\xi$ é o coeficiente de atrito de dij.

Para estimar a distância entre os municípios, foi calculada a distância geodésica ortodrômica entre as coordenadas (latitude e longitude) de suas sedes. Essas estimativas foram, ainda, calibradas em função de um coeficiente de atrito, calculado com base nos movimentos migratórios dessas localidades, segundo a seguinte equação:

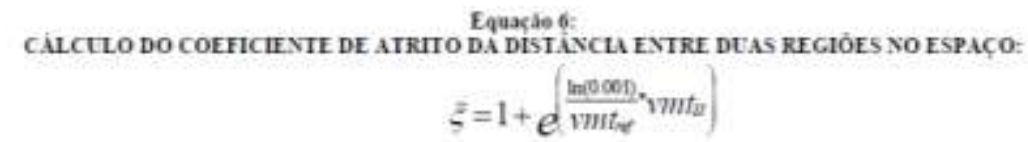

na qual: $\xi$ é o coeficiente de atrito da distância geodésica entre a região i e a região j; vmtij representa o volume migratório total entre a região i e a região j, em um dado período e vmtref. é um volume migratório de referência.

Tem-se, portanto, que o índice de interação entre um polo socioeconômico e os demais municípios é dado, segundo o modelo gravitacional de regionalização socioeconômica, aqui proposto, pela razão direta do produto de suas populações com seus respectivos Índices de Desenvolvimento socioeconômico e pela razão inversa da distância ente eles, elevada a um coeficiente específico de atrito $\xi$, tal como o proposto por ISARD (1975, p 48-50). 


\section{2 - CARACTERIZAÇÃO DO ESPAÇO SÓCIOECONÔMICO DOS MUNICÍPIOS} AMAZÔNICOS

\section{Índice de Concentração e Dinâmica Demográfica}

O índice de Concentração e Dinâmica Demográfica correspondeu ao grau de pertinência (gik) dos municípios amazônicos ao perfil puro de máxima concentração demográfica. Como os gik foram estimados para dois perfis extremos, o perfil de máxima concentração demográfica foi aquele que caracterizado pela alta probabilidade de ocorrência do substrato mais elevados das variáveis que compõem essa dimensão tal como pode ser percebido na TABELA 2. Esse perfil apresenta elevada probabilidade de ocorrência das seguintes características: população elevada, alta densidade demográfica, alto grau de urbanização e elevadas taxas de crescimento.

TABELA 2

ÍNDICE DE CONCENTRAÇÃO E DINÂMICA DEMOGRÁFICA: PROBABILIDADES DOS SUBSTRATOS DAS VARIÁVEIS DE SEREM PREVALENTES AOS PERFIS PUROS

\begin{tabular}{|c|c|c|c|c|c|c|c|c|c|c|}
\hline \multirow[t]{2}{*}{ Índice de Concentração e Dinâmica Demográfica } & \multicolumn{5}{|c|}{$\begin{array}{l}\text { Primeiro } \\
\text { Perfil Puro } \\
\end{array}$} & \multicolumn{5}{|c|}{$\begin{array}{l}\text { Segundo } \\
\text { Perfil Puro }\end{array}$} \\
\hline & 1 & 2 & 3 & 4 & 5 & 1 & 2 & 3 & 4 & 5 \\
\hline Poppulagào Total Desaidade Demogrifica Gizan de Uthanizagào & 0 & 0 & 0 & 0 & 1 & 1 & 0 & 0 & 0 & 0 \\
\hline \multirow[t]{3}{*}{ Twa Anual de Crescimento } & 0 & 0 & 0 & 0 & 1 & 1 & 0 & 0 & 0 & 0 \\
\hline & 0 & 0 & 0 & 0 & 1 & 1 & 0 & 0 & 0 & 0 \\
\hline & 0 & 0 & 0 & 0 & 1 & 1 & 0 & 0 & 0 & 0 \\
\hline
\end{tabular}

Dos 792 municípios que compõem a Amazônia Brasileira, 22,7\% apresentaram, numa escala de zero a um, índices de concentração demográfica inferior a 0,$4 ; 57,6 \%$, entre 0,4 e 0,8 e, somente, $19,7 \%$ apresentaram índices superiores a 0,8, tal como revela a analise da Fig. 1.

A distribuição espacial desses índices segue o padrão determinado pelas grandes vias de acesso aos grandes centros econômicos da região, tais como Belém, Manaus e Cuiabá.

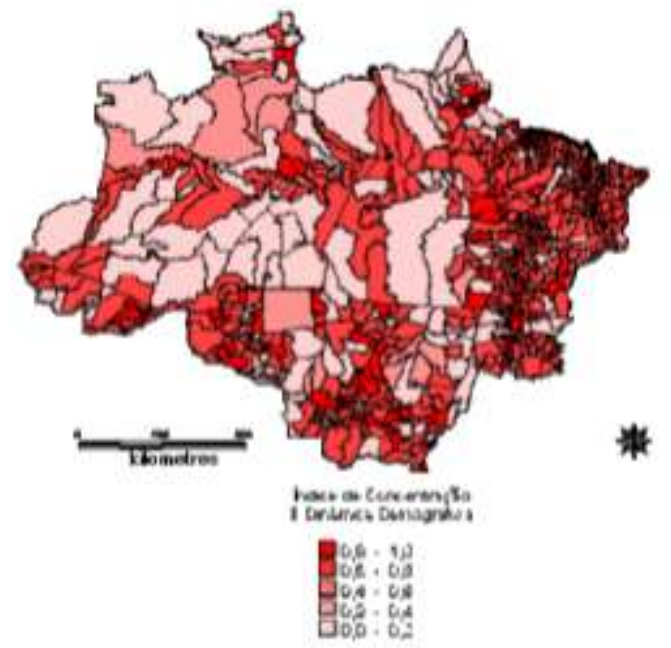

Fig. 1. Amazônia Brasileira - Índices de Concentração Demográfica dos Municípios Amazônicos.

Fonte: Malha digital dos municípios brasileiros - IBGE (2000). 


\section{Índice de Desenvolvimento Econômico}

Para obtenção dos índices de Desenvolvimento Econômico, empregaram-se os mesmos procedimentos para obtenção dos índices de Concentração Demográfica, agora, aplicados às variáveis dessa dimensão. O perfil de máximo desenvolvimento econômico (primeiro perfil puro) apresenta elevada probabilidade de ocorrência das seguintes características: elevado número de agências bancárias, elevados montantes de depósitos bancários e de aplicações no mercado financeiro, alta receita e despesa orçamentária e elevados montantes proveniente de impostos territorial rural e do Fundo de Participação dos Municípios (TABELA 3).

Os municípios da região amazônica brasileira, tal como o restante do Brasil, apresentaram, no quesito índice de desenvolvimento econômico, grande assimetria de sua distribuição, tal como é indicado na análise da Fig. 2. Menos de 10,0\% desses municípios apresentaram índices de desenvolvimento econômico superiores a 0,8 e menos de 25,0\%, superiores a 0,2 , ou seja, mais de 75,0\% apresentam baixíssimo desempenho no que tange as atividades econômicas.

TABELA 3

\begin{tabular}{|c|c|c|c|c|c|c|c|c|c|c|}
\hline \multirow[t]{2}{*}{ Indice de Desenvolvimento Econômico } & \multicolumn{5}{|c|}{$\begin{array}{l}\text { Primeiro Perfil } \\
\text { Puro }\end{array}$} & \multicolumn{5}{|c|}{$\begin{array}{l}\text { Segundo Perfil } \\
\text { Puro }\end{array}$} \\
\hline & 1 & 2 & 3 & 4 & 5 & 1 & 2 & 3 & 1 & 5 \\
\hline Produto Intemo Bruto - 1996 & 0 & 0 & 0 & 0 & 1 & 1 & 0 & 0 & 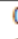 & 0 \\
\hline Produto Intemo Bruto: setor primário - 1996 Produto Intemo & 0 & 0 & 0 & 0 & 1 & 1 & 0 & 0 & & 0 \\
\hline Bruto: setor secundáro - 1996 Produto Intemo Bruto: setor & 0 & 0 & 0 & 0 & 1 & 1 & 0 & 0 & & 0 \\
\hline terciário - 1996 Número de Agências Bancárias & 0 & 0 & 0 & 0 & 1 & 1 & 0 & 0 & & 0 \\
\hline Valor dos depósitos Bancírios Valor das Aplicações - 1998 & 0 & 0 & 0 & 0 & 1 & 1 & 0 & 0 & & 0 \\
\hline Receitas orçamentínias realizadas - 1997 Despesas & 0 & 0 & 0 & 0 & 1 & 1 & 0 & 0 & & 0 \\
\hline orçamentárias realizadas - 1997 Valor do Fundo de & 0 & 0 & 0 & 0 & 1 & 1 & 0 & 0 & & 0 \\
\hline Participação dos Municípios & 0 & 0 & 0 & 0 & 1 & 1 & 0 & 0 & & 0 \\
\hline \multirow[t]{3}{*}{ Valor do Imposto Territorial Rural - 1998} & 0 & 0 & 0 & 0 & 1 & 1 & 0 & 0 & can & 0 \\
\hline & 0 & 0 & 0 & 0 & 1 & 1 & 0 & 0 & & 0 \\
\hline & 0 & 0 & 0 & 0 & 1 & 1 & 0 & 0 & & 0 \\
\hline
\end{tabular}

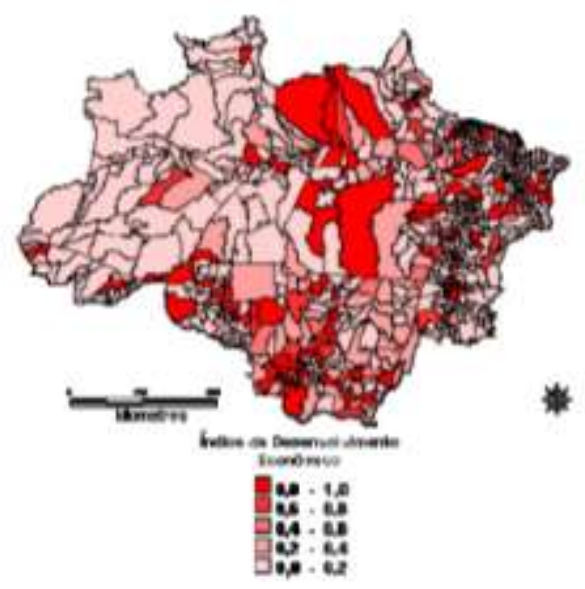

Fig. 2. Amazônia Brasileira - Índices de Desenvolvimento Econômico dos Municípios Amazônicos.

Fonte: Malha digital dos municípios brasileiros - IBGE (2000).

Cadernos do Leste

Artigos Cientificos

Belo Horizonte, Jan.-Dez. Vol.9, n 2009 


\section{Índice de Infraestrutura Agrária}

O perfil de máxima infraestrutura agrária (primeiro perfil puro) apresenta elevada probabilidade de ocorrência das seguintes características: Alto valor da produção animal e vegetal; elevado número de máquinas agrícolas, caminhões e utilitários, tal como pode ser observado na TABELA 4.

TABELA 4

ÍNDICE DE INFRA-ESTRUTURA AGRÁRIA: PROBABILIDADES DOS SUBSTRATOS DAS VARIÁVEIS DE SEREM PREVALENTES AOS PERFIS PUROS

\begin{tabular}{|c|c|c|c|c|c|c|c|c|c|c|}
\hline \multirow[t]{2}{*}{ Índice de Infraestrutura agrária } & \multicolumn{5}{|c|}{$\begin{array}{l}\text { Primeiro Perfil } \\
\text { Puro }\end{array}$} & \multicolumn{5}{|c|}{$\begin{array}{l}\text { Segundo Perfil } \\
\text { Puro }\end{array}$} \\
\hline & 1 & 2 & 3 & 4 & 5 & 1 & 2 & 3 & 4 & 5 \\
\hline Valor da produçĩo aninul e vegetal Total de Tratores & 0 & 0 & 0 & 0 & 1 & 1 & 0 & 0 & 0 & 0 \\
\hline Total Máquinas de plantio Total de collheitadeiras Total de & 0 & 0 & 0 & 0 & 1 & 1 & 0 & 0 & 0 & 0 \\
\hline Caminhões & 0 & 0 & 0 & 0 & 1 & 1 & 0 & 0 & 0 & 0 \\
\hline \multirow[t]{3}{*}{ Total de Utilitários } & 0 & 0 & 0 & 0 & 1 & 1 & 0 & 0 & 0 & 0 \\
\hline & 0 & 0 & 0 & 0 & 1 & 1 & 0 & 0 & 0 & 0 \\
\hline & 0 & 0 & 0 & 0 & 1 & 1 & 0 & 0 & 0 & 0 \\
\hline
\end{tabular}

Do total municípios que compõem a Amazônia Brasileira, 53,8\% apresentaram índices de infraestrutura agrária inferior a 0,2; 28,8\%, entre 0,2 e 0,8 e, apenas, $17,4 \%$ apresentaram índices superiores a 0,8, tal como revela a análise da Fig. 3. Entretanto, o que chama a atenção é que a maioria dos municípios com elevada infraestrutura agrária situa-se na região do estado do Mato Grosso. Isso sugere que o estado já tenha passado sua fase de fronteira agrícola e se estabelecido como região agrícola consolidada (Fig. 3).

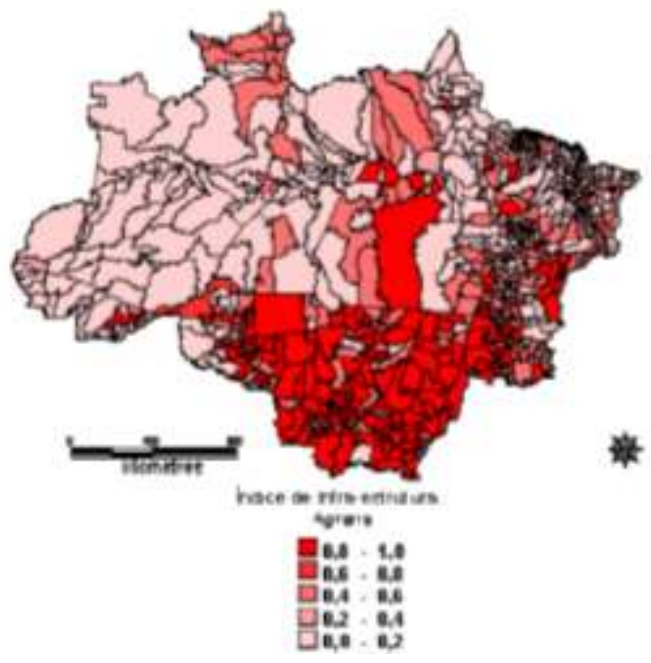

Fig.3. Amazônia Brasileira-Índices de Infraestrutura agrária dos Municípios Amazônicos.

Fonte: Malha digital dos municípios brasileiros-IBGE(2000).

Cadernos do Leste

Artigos Cientificos

Belo Horizonte, Jan.-Dez. Vol.9, n9, 2009 


\section{Indice de Atividade Agropecuária e de Extração Madeireira}

O perfil de máxima atividade agropecuária e da extração madeireira (primeiro perfil puro) apresenta elevada probabilidade de ocorrência das seguintes características: baixa área total dos estabelecimentos agropecuários com área inferior a $200 \mathrm{Ha}$, elevada área total dos estabelecimentos agropecuários com área superior a $200 \mathrm{Ha}$, elevado índice de concentração fundiária (esse índice resulta da relação entre o total da área ocupada pelos estabelecimentos agropecuários de área total inferior a $200 \mathrm{Ha}$ e a área total ocupada por todos estabelecimentos agropecuários do município), elevado efetivo do rebanho e elevadas taxas anuais de crescimento desse efetivo; elevada densidade das taxas anuais de crescimento das lavouras e elevado número de industria madeireiras e de extração de Madeira, em tora, por ano e grande quantidade de área afetada pela extração de madeira (TABELA 5).

TABELA 5

ÍNDICE DE ATIVIDADE AGROPECUÁRIA E DE EXTRAÇÃ̃O MADEIREIRA: PROBABILIDADES DOS SUBSTRATOS DAS VARIÁVEIS DE SEREM PREVALENTES AOS PERFIS PUROS

\begin{tabular}{|c|c|c|c|c|c|c|c|c|c|c|}
\hline \multirow{2}{*}{ Índice de Atividade Agropecuária e de Extração Madereira } & \multicolumn{5}{|c|}{$\begin{array}{l}\text { Primeiro } \\
\text { Perfil Puro }\end{array}$} & \multicolumn{5}{|c|}{$\begin{array}{l}\text { Segundo } \\
\text { Perfil Puro }\end{array}$} \\
\hline & 1 & 2 & 3 & 4 & 5 & 1 & 2 & 3 & 4 & \\
\hline Área total dos estabeleclemtnao agropoecuarilos com area Inferlor a $200 \mathrm{Ha}$. Area total dos estabeleclemtnso & 1 & 0 & 0 & 0 & 0 & 0 & 0 & 0 & 0 & \\
\hline Efetlvo do Rebanho & 0 & 0 & 0 & 0 & 1 & 1 & 0 & 0 & 0 & \\
\hline Taxa anual de creacimento do Efettivo do Rebanho Densidade das lavouras & 0 & 0 & 0 & 0 & 1 & 1 & 0 & 0 & 0 & \\
\hline Taxa anual de crescimento das lavouras Número de Industrla madelrelras Estraçăo de Madelra em tora por ano & 0 & 0 & 0 & 0 & 1 & 1 & 0 & 0 & 0 & \\
\hline \multirow[t]{3}{*}{ Area Afetada } & 0 & 0 & 0 & 0 & 1 & 1 & 0 & 0 & 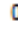 & \\
\hline & 0 & 0 & 0 & 0 & 1 & 1 & 0 & 0 & 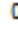 & \\
\hline & 0 & 0 & 0 & 0 & 1 & 1 & 0 & 0 & 0 & \\
\hline
\end{tabular}

Os municípios da região amazônica brasileira apresentaram uma distribuição dos seus índices de desenvolvimento socioeconômico quase tão assimétrica quanto aquela observada na do índice de desenvolvimento econômico (Fig.4), tal como o observado na análise da Fig. 2. O que corrobora com a grande correlação entre essas duas dimensões. Menos de 9,0\% desses municípios apresentaram índices de pressão das atividades agropecuária e de extração madeireira superiores a 0,8 e menos de 39,0\%, superiores a 0,2 , ou seja, mais de $61,0 \%$ apresentam baixíssimo nível de pressão provenientes de atividades da agropecuária e da extração madeireira. 


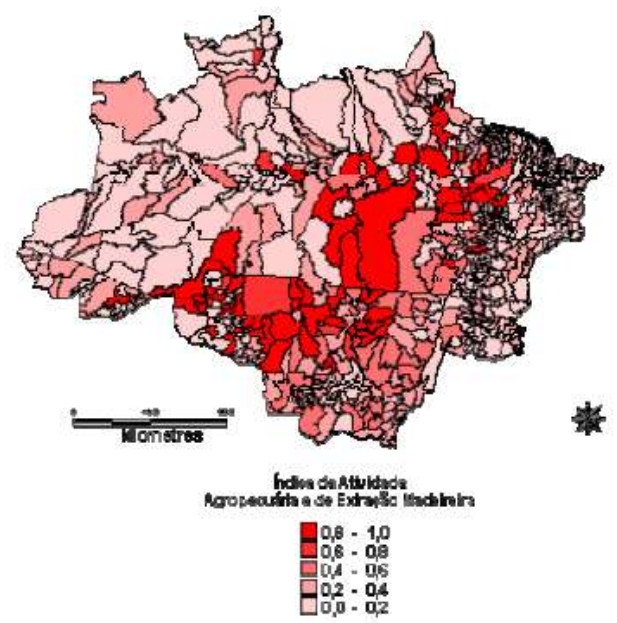

Fig. 4. Amazônia Brasileira - Índices de Atividade Agropecuária e de Extração Madeireira dos Municípios Amazônicos. Fonte: Malha digital dos municípios brasileiros - IBGE (2000).

\section{Índice de Desenvolvimento Social}

A TABELA 6 revela que o perfil de máximo desenvolvimento social (primeiro perfil puro) apresenta elevada probabilidade de ocorrência das seguintes características: elevada média de anos de estudo de sua população; elevado numero de hospitais, de postos e de centros de saúde; alta incidência de domicílios com abastecimento de água e esgotamento sanitário ligados à rede geral; grande percentual de domicílios equipados com luz elétrica, televisores e telefones; bem como grande percentual de suas vias públicas pavimentadas e iluminadas.

Do total municípios que compõem a Amazônia Brasileira, 58,8\% apresentaram índices de desenvolvimento social inferior a 0,$4 ; 37,5 \%$, entre 0,4 e 0,8 e, apenas, $3,6 \%$ apresentaram índices superiores a 0,8, tal como indica a análise da Fig. 5. 
TABELA 6

ÍNDICE DE DESENVOLVIMENTO SOCIAL: PROBABILIDADES DOS SUBSTRATOS DAS VARIÁVEIS DE SEREM PREVALENTES AOS PERFIS PUROS

\begin{tabular}{|c|c|c|c|c|c|c|c|c|c|c|}
\hline \multirow[t]{2}{*}{ Índice de Desenvolvimento Social } & \multicolumn{5}{|c|}{$\begin{array}{l}\text { Primeiro } \\
\text { Perfil Puro }\end{array}$} & \multicolumn{5}{|c|}{$\begin{array}{l}\text { Segundo } \\
\text { Perfil Puro }\end{array}$} \\
\hline & 1 & 2 & 3 & 4 & 5 & 1 & 2 & 3 & 4 & \\
\hline Anos de estudo - pessoss residentes - 7 a 14 anos de Idade - madla Anos de estudo - pessoss residentes - 15 a 24 & 0 & 0 & 0 & 0 & 1 & 1 & 0 & 0 & 0 & 0 \\
\hline anos de Idade - médla Anos de ertudo - Chefes de Domicillos - mélla & 0 & 0 & 0 & 0 & 1 & 1 & 0 & 0 & 0 & 0 \\
\hline Hospitals (por 1000 habitantes) & 0 & 0 & 0 & 0 & 1 & 1 & 0 & 0 & 0 & 0 \\
\hline Leitos hospitalares (por 1000 habitantes) Unldades ambulatorials (por 1000 habitantes) Postos de saude (por 1000 & 0 & 0 & 0 & 0 & 1 & 1 & 0 & 0 & 0 & 0 \\
\hline habitantes) Centros de saude (por 1000 habltantes) Consultorios medlcos (por 1000 habitantes) & 0 & 0 & 0 & 0 & 1 & 1 & 0 & 0 & c & \\
\hline Consultorios odontologicos (por 1000 habltantes) Ambulatorios de unidade hospltalar geral (por 1000 habitantes) & 0 & 0 & 0 & 0 & 1 & 1 & 0 & 0 & 0 & 0 \\
\hline Postos de assistencla medica (por 1000 habitantes) Internaçoes hospitalares (por 1000 habitantea) & 0 & 0 & 0 & 0 & 1 & 1 & 0 & 0 & c & 0 \\
\hline Total de Domicillos & 0 & 0 & 0 & 0 & 1 & 1 & 0 & 0 & 0 & 0 \\
\hline Domicllios Particulares Improvisados Domicillos Coletivos & 0 & 0 & 0 & 0 & 1 & 1 & 0 & 0 & o & 0 \\
\hline Domlcillos particulares permanentes - forma de abastecimento de agua - rede geral Domiclllos particulares & 0 & 0 & 0 & 0 & 1 & 1 & 0 & 0 & c & 0 \\
\hline permanentes - com banheiro ou sanitario & 0 & 0 & 0 & 0 & 1 & 1 & 0 & 0 & c & 0 \\
\hline Domiclllos particulares permanentes - com banheiro ou sanitario - esgotamento sanitario - rede geral Domicillos & 0 & 0 & 0 & 0 & 1 & 1 & 0 & 0 & c & 0 \\
\hline particulares permanentes - destino de llixo - coletado & 0 & 0 & 0 & 0 & 1 & 1 & 0 & 0 & o & 0 \\
\hline Domlelllos particulares permanentes - exiaténcla de luz elatrica Wedla de Televisores por domlclllo & 0 & 0 & 0 & 0 & 1 & 1 & 0 & 0 & 0 & 0 \\
\hline Domlcillos particulares permanentes - existencla de Telefone Vlas Urbanas Pavimentadas & 0 & 0 & 0 & 0 & 1 & 1 & 0 & 0 & c & 0 \\
\hline \multirow{10}{*}{ Vlas Urbanas lluminadas } & 0 & 0 & 0 & 0 & 1 & 1 & 0 & 0 & 0 & 0 \\
\hline & 0 & 0 & 0 & 0 & 1 & 1 & 0 & 0 & 0 & 0 \\
\hline & 0 & 0 & 0 & 0 & 1 & 1 & 0 & 0 & 0 & 0 \\
\hline & 0 & 0 & 0 & 0 & 1 & 1 & 0 & 0 & 0 & 0 \\
\hline & 0 & 0 & 0 & 0 & 1 & 1 & 0 & 0 & 0 & 0 \\
\hline & 0 & 0 & 0 & 0 & 1 & 1 & 0 & 0 & 0 & 0 \\
\hline & 0 & 0 & 0 & 0 & 1 & 1 & 0 & 0 & 0 & 0 \\
\hline & 0 & 0 & 0 & 0 & 1 & 1 & 0 & 0 & 0 & 0 \\
\hline & 0 & 0 & 0 & 0 & 1 & 1 & 0 & 0 & 0 & 0 \\
\hline & 0 & 0 & 0 & 0 & 1 & 1 & 0 & 0 & 0 & 0 \\
\hline
\end{tabular}

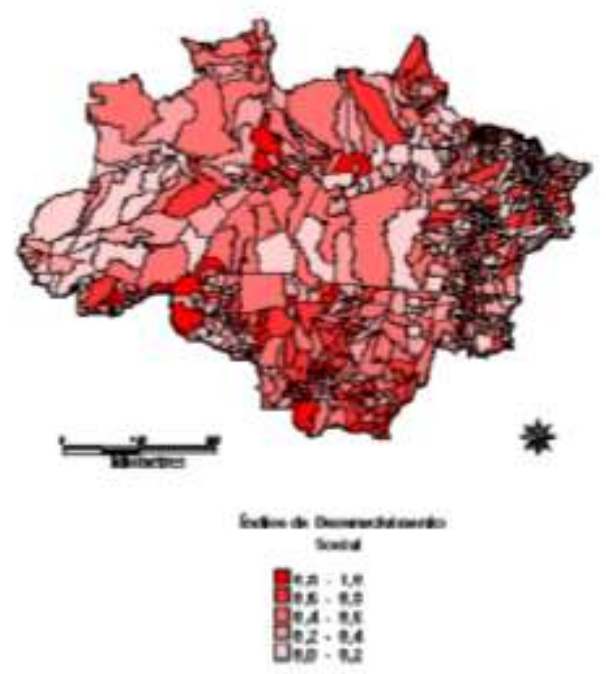

Fig. 5. Amazônia Brasileira - Índices de Desenvolvimento Social dos Municípios Amazônicos. Fonte: Malha digital dos municípios brasileiros - IBGE (2000).

\section{Índice de Desenvolvimento Socioeconômico e Classificação dos Municípios da}

\section{Amazônia Brasileira}

Por fim, o perfil de máximo desenvolvimento socioeconômico foi obtido através combinação de todos os outros índices e apresenta elevada probabilidade de ocorrência das seguintes características: elevados índices de concentração demográfica, de desenvolvimento econômico, de infraestrutura agrária índice e de pressão da atividade agropecuária e de extração madeireira, tal como pode ser observado na TABELA. 7. 
TABELA 7

ÍNDICE DE DESENVOLVIMENTO SÓCIO-ECONÔMICO: PROBABILIDADES DOS SUBSTRATOS DAS VARIÁVEIS DE SEREM PREVALENTES AOS PERFIS PUROS

\begin{tabular}{|c|c|c|c|c|c|c|c|c|c|c|}
\hline \multirow[t]{2}{*}{ Índice de Desenvolvimento Sócio-econômico } & \multicolumn{5}{|c|}{$\begin{array}{l}\text { Primeiro } \\
\text { Perfil Puro }\end{array}$} & \multicolumn{5}{|c|}{$\begin{array}{l}\text { Segundo } \\
\text { Perfil Puro }\end{array}$} \\
\hline & 1 & 2 & 3 & 4 & 5 & 1 & 2 & 3 & 4 & 5 \\
\hline Indice de Concentraça $\theta$ Dindmica Demografica Indlce de Desenvolvimento Econômlco & 0 & 0 & 0 & 0 & 1 & 1 & 0 & 0 & 0 & 0 \\
\hline Indice de infra estrutura agrarla & 0 & 0 & 0 & 0 & 1 & 1 & 0 & 0 & 0 & 0 \\
\hline Indlce de Atlvidade Agropecuarria e de Extraçæo Vegetal & 0 & 0 & 0 & 0 & 1 & 1 & 0 & 0 & 0 & 0 \\
\hline \multirow[t]{2}{*}{ Indice de Desenvolvimento Social } & 0 & 0 & 0 & 0 & 1 & 1 & 0 & 0 & 0 & 0 \\
\hline & 0 & 0 & 0 & 0 & 1 & 1 & 0 & 0 & 0 & 0 \\
\hline
\end{tabular}

O mapeamento dos índices de desenvolvimento socioeconômico revelou o que pode ser considerado a síntese de todos os índices anteriores e, consequentemente, de todos os 29 indicadores utilizados em sua construção. Como houve duas dimensões, cuja distribuição de seus índices foi muito assimétrica, o mesmo ocorreu com o índice de desenvolvimento socioeconômico, porém de modo não tão acentuado. Do total dos municípios amazônicos, $55,4 \%$ apresentaram índices de desenvolvimento socioeconômico inferior a 0,$2 ; 33,0 \%$, entre 0,2 e 0,8 e, apenas, $11,4 \%$ apresentaram índices superiores a 0,8. Os municípios foram, enfim, classificados de acordo com seu índice de desenvolvimento socioeconômico. Empregaram-se, nessa classificação, os seguintes critérios: municípios de desenvolvimento socioeconômico baixo, municípios cujos índices variaram entre 0,00 e 0,25; municípios de desenvolvimento socioeconômico médio baixo, municípios cujos índices variaram entre 0,25 e 0,33; municípios de desenvolvimento socioeconômico médio, municípios cujos índices variaram entre 0,33 e 0,66; municípios de desenvolvimento socioeconômico médio alto, municípios cujos índices variaram entre 0,66 e 0,75 e municípios de desenvolvimento socioeconômico alto, municípios cujos índices variaram entre 0,75 e 1,00 (Fig. 6). 


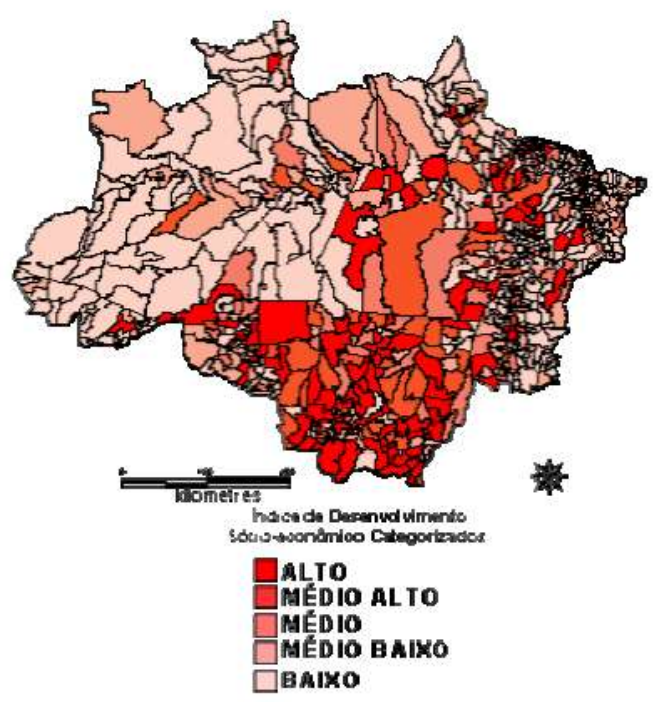

Fig. 6. Amazônia Brasileira - Índices de Desenvolvimento Socioeconômico Categorizados dos Municípios Amazônicos. Fonte: Malha digital dos municípios brasileiros - IBGE (2000).

A Regionalização Socioeconômica dos Municípios Brasileiros

A regionalização socioeconômica baseia-se na articulação de quatro componentes: uma hierarquia urbana dos centros econômicos da região, o nível de desenvolvimento socioeconômico de todas as áreas consideradas, a distância entre os pólos econômicos e as demais áreas classificadas como não-pólos econômicos e os movimentos migratórios entre eles. Esses quatro elementos integraram, conforme o mencionado na seção 3, o modelo gravitacional de regionalização.

Como o nível de desenvolvimento socioeconômico foi o tema de toda a seção anterior, tratar-se-á, aqui, da caracterização da hierarquia urbana da Amazônia brasileira e dos movimentos migratórios entre seus municípios. Feito isso, estimar-se-ão as distancias geodésicas entre as sedes municipais das áreas em questão e, assim, todos os elementos necessários para a modelagem e caracterização das áreas de influência socioeconômica dos pólos amazônicos estarão definidos. Por últimos, esses resultados serão georreferenciados, o que permitirá que se efetue analises espaciais das macros, mesos e microrregiões dos pólos amazônicos e afim de que se conheça sua rede de cidades.

O primeiro passo para uma proposta de regionalização socioeconômica dos municípios amazônicos foi a identificação dos municípios que atuam como macro, meso e micropolos. Através dos índices de terciarização ajustado (ITa), tem-se um bom critério classificatório para esses municípios. Entretanto, como áreas economicamente densas e diversificadas tendem a trasbordar essas atividades para seus vizinhos, também empregou-se critérios qualitativos e funcionais para a definição dos pólos econômicos da Amazônia brasileira. Para a definição dos macropolos econômicos, por exemplo, adotou-se, levando em consideração os índices de Cadernos do Leste 
terceirização ajustado e a importância político-administrativa, as capitais das unidades da federação que compõem esse estudo.

Os municípios definidos, portanto, como macropolos econômicos regionais da Amazônia brasileira foram: São Luiz, Cuiabá, Porto Velho, Rio Branco, Manaus, Boa Vista, Belém, Macapá e Palmas. Nesse, caso, apenas Palmas foi inserida levando-se também em consideração suas funções político-administrativas, os demais se inseriram devido ao peso de seus ITa, que apresentavam valores superiores a $20 \%$.

Para se identificar os mesopolos regionais, optou-se por trabalhar com os municípios não-contíguos entre si e que apresentassem ITa superiores a 4,2\%. Chegou-se, então, a um total de 19 municípios que, devido ao peso de seu setor terciário, agiriam como mesopolos regionais, são eles: Belém, Cuiabá, Porto Velho, São Luís, Manaus, Rio Branco, Macapá, Boa Vista, Rondonópolis, Ji-Paraná, Imperatriz, Palmas, Santarém, Sinop, Cacoal, Marabá, Cáceres, Barra do Garças e Vilhena2. Foram identificados, contudo, mais nove municípios como mesopolos regionais, devido a suas características em relação aos seus vizinhos e posição geográfica: Parauapebas, Tangará da Serra, Gurupi, Caxias, Bacabal, Tucuruí, Cruzeiro do Sul, Araguaína e Tefé.

Por último, os critérios utilizados para a finalização dessa hierarquia urbana, no nível microrregional, foram índice de terceirização superior a $0,5 \%$ e não contiguidade dos municípios entre si. Dessa forma, dos 792 municípios 116 foram classificados como possíveis micropolos regionais. Efetuadas as análises qualitativas, nas quais também levou-se em consideração a importância da localização geográfica do município em relação aos seus vizinhos, chegou-se a um total de 48 micropolos regionais: os micropolos de Belém, Cuiabá, Porto Velho, São Luís,Manaus,Rio Branco,Macapá, BoaVista e Palmas(que são também macro e meso pólos regionais); os micropolos de Rondonópolis, Ji-Paraná, Imperatriz, Santarém,Sinop,Cacoal,Marabá,Cáceres,BarradoGarças, Vilhena,Parauapebas,Tangará daSerra,Gurupi,Caxias,Bacabal,Tucuruí,CruzeirodoSul,AraguaínaeTefé(que também são meso pólos regionais); e, por fim os micropolos de Guajará-Mirim, Jaru, Redenção, Altamira,Codó, Juína, Itaituba, Barrado Corda, Paragominas, Almeirim, Pontes eLacerda, Balsas,AltaFlorestaD'Oeste,Colíder,Juara,Breves,Parintins,GuarantãdoNorte. Ariquemes e Alta Floresta.

A tabela a baixo (TAB.2) mostra a relação completa dos 48 pólos regionais, identificandoo quanto sua funcionalidade, ou seja, em termos de macromeso e micropolos econômicos,bem como traz também o valor de seus PIB setorizados e seus índices de terceirização. 
TABELA 8

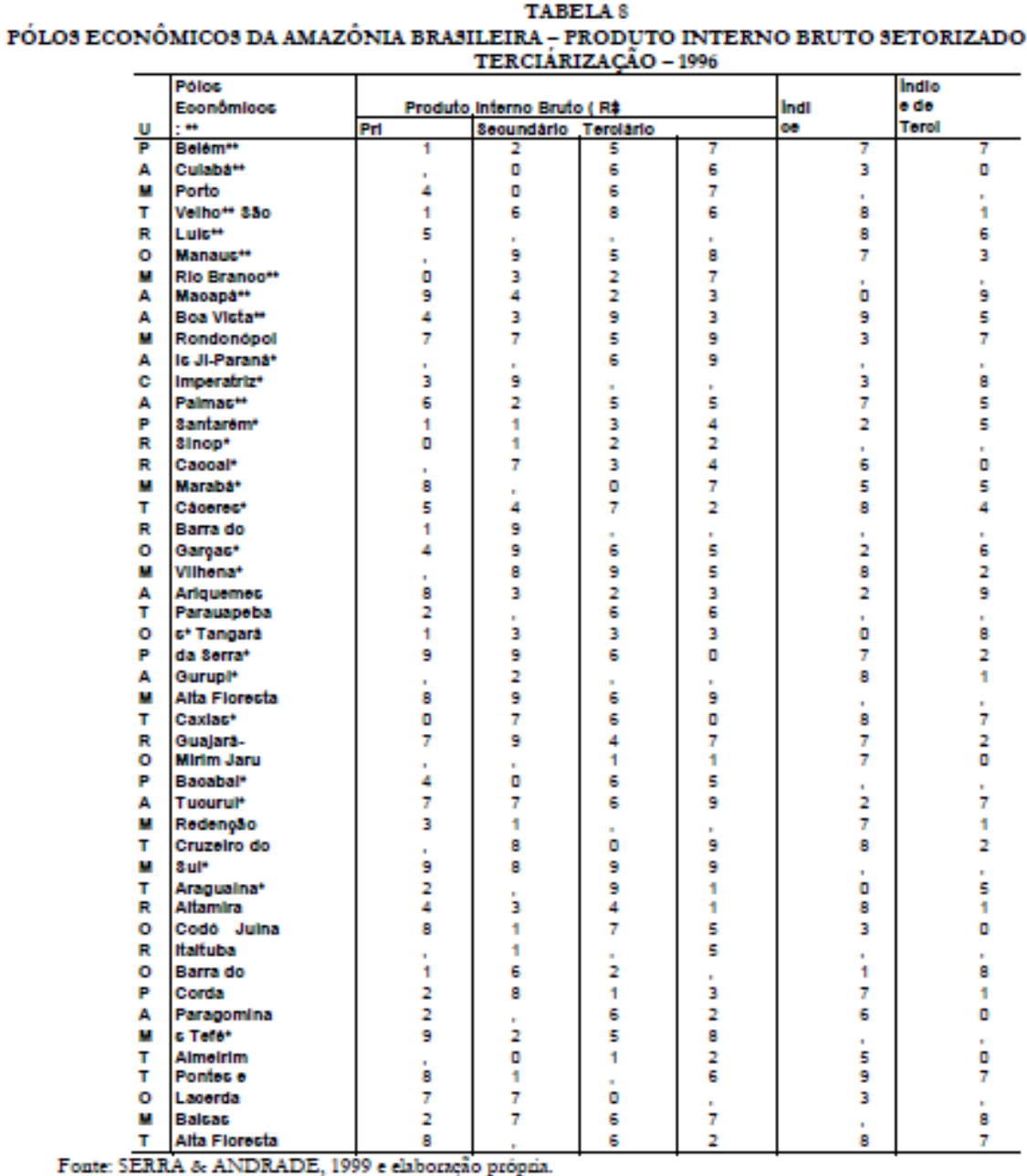

\section{Os movimentos migratórios entre os municípios amazônicos brasileiros}

Os Censos Demográficos de 1980, 1991 e 2000 produzem boas estatísticas de movimentos migratórios intermunicipais e que podem ser agregados,de modo a indicar os movimentos populacionais ocorridos entre as microrregiões brasileiras em determinados períodos.Esses dados permitem, ainda, que esses movimentos possam ser ponderados e/ou controlados,segundo diversas informações socioeconômicas-tais como idade, renda, escolaridade, etc.-dos indivíduos recenseados. Para efeitos desse estudo, utilizou-se os micro dados do Censo Demográfico de 2000 na estimação dos movimentos migratórios entre os municípios amazônicos, entre 1995 e 2000.

Esses movimentos populacionais foram estimados com base no quesito referente ao local de residência exatamente cinco anos atrás à data de referência da pesquisa, isto é, em 
1/08/1995. São considerados imigrantes de uma determinada unidade geográfica, todos aqueles que residiam fora dela em 1/08/1995 e nela residiam em 1/08/2000. Simetricamente, seus emigrantes são aqueles que nela residiam em 1/08/1995 e residiam em outra unidade geográfica em 1/08/2000. Trata-se de imigrantes e emigrantes de 'data fixa', cuja diferença, por um lado, corresponde ao verdadeiro conceito de saldo migratório e a soma, por outro, ao volume mais preciso das trocas migratórias entre duas localidades durante o período de referência (GARCIA, 2002).

Foram estimados, portanto, os volumes migratórios entre todos os 48 municípios classificados como pólos regionais e os demais 744 municípios que compõem a Amazônia brasileira, ou seja, foi levantado o número de imigrantes e emigrantes de cada polo econômico com cada um dos 791 municípios restantes. A TAB. 3 traz o volume total movimentos migratórios entre os municípios amazônicos que tiveram como origem ou destino os pólos econômicos, ou seja, o total de imigrantes e emigrantes dos respectivos pólos, bem como o saldo migratório e o volume total desses movimentos, entre 1995 e 2000. 
Tabela 3

AMAZÔNIA BRASILEIRA 2000 - NÚMERO TOTAL DE IMIGRANTES, EMIGRANTES, SALDO E VOLUME MIGRATÓRIO ENTRE PÓLOS ECONÔMICOS E DEMAIS MUNICÍPIOS AMAZÔNICOS - 1995/2000

\begin{tabular}{|c|c|c|c|c|c|}
\hline U & $\begin{array}{c}\text { Polos } \\
\text { Economl }\end{array}$ & $\mathrm{Em}$ & Im & $\begin{array}{l} \\
\text { al }\end{array}$ & $\begin{array}{l}\text { Vo } \\
\text { lu }\end{array}$ \\
\hline $\begin{array}{l}\mathbf{P} \\
\mathrm{A}\end{array}$ & $\begin{array}{l}\text { Belem Culaba } \\
\text { Porto Velho }\end{array}$ & $\begin{array}{l}1 \\
0\end{array}$ & $\begin{array}{l}5 \\
7\end{array}$ & - & $\begin{array}{l}1 \\
6\end{array}$ \\
\hline M & sao Luls & 5 & . & 8 & 3 \\
\hline $\mathbf{T}$ & Manaus & 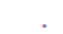 & 4 & & \\
\hline $\mathbf{R}$ & Rlo Branco & 8 & 3 & 3 & 2 \\
\hline 0 & Мacapa Boa & 0 & 2 & 7 & 4 \\
\hline M & Vista & 9 & 2 & 7 & 1 \\
\hline A & Rondonopolls & 3 & 4 & - & 5 \\
\hline M & JI-Parana & 4 & . & 1 & 8 \\
\hline A & Imperatrlz & . & 2 & 0 & . \\
\hline A & Paimas & 6 & 0 & . & 8 \\
\hline c & Santarem & 9 & 1 & 4 & 9 \\
\hline A & Sinop & 6 & 2 & 9 & 7 \\
\hline $\mathbf{P}$ & Cacoal & 1 & 0 & 5 & 4 \\
\hline $\mathbf{R}$ & Maraba & 9 & . & 1 & 0 \\
\hline $\mathbf{R}$ & Caceres & . & 9 & . & . \\
\hline M & Barra do & 0 & 3 & 8 & 0 \\
\hline T & Garças & 8 & 5 & 4 & 2 \\
\hline $\mathbf{R}$ & VIlhena & 7 & 5 & 8 & 2 \\
\hline 0 & Arlquemes & 4 & 5 & 7 & 1 \\
\hline M & Parauapebas & 8 & . & . & 0 \\
\hline A & Tangara da & . & 4 & 1 & 3 \\
\hline T & Serra Gurupl & 3 & 7 & 4 & . \\
\hline 0 & Alta Floresta & 3 & 9 & 6 & 8 \\
\hline $\mathbf{P}$ & Caxlas & 3 & 8 & 4 & 1 \\
\hline A & Guajara-MIrım & 4 & 5 & 0 & 2 \\
\hline M & Jaru & 4 & 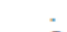 & 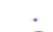 & 1 \\
\hline T & Bacabal & . & 5 & 6 & 3 \\
\hline $\mathbf{R}$ & Tucurul & 9 & 6 & 0 & 0 \\
\hline 0 & Redençăo & 6 & 9 & 5 & . \\
\hline $\mathbf{P}$ & Cruzelro do & 4 & 1 & 3 & 5 \\
\hline A & Sul Araguaina & 1 & 5 & . & 3 \\
\hline M & Altamira & 1 & . & 9 & 3 \\
\hline T & Codo Juina & . & 8 & 6 & 2 \\
\hline M & Italtuba & 9 & 8 & 6 & 7 \\
\hline $\begin{array}{ll}\mathrm{T} \\
\mathrm{l}\end{array}$ & Barra do & 2 & 8 & 1 & . \\
\hline $\mathbf{R}$ & Corda & 2 & 2 & 6 & 8 \\
\hline 0 & Paragominas & 1 & 8 & . & 1 \\
\hline $\mathbf{R}$ & Tefe & 2 & . & 4 & 0 \\
\hline 0 & Almeirim & . & 7 & 0 & 4 \\
\hline $\mathbf{P}$ & Pontes e & 3 & 6 & 0 & 1 \\
\hline A & Lacerda & 6 & 4 & 1 & . \\
\hline M & Balsas & 4 & 2 & 8 & 1 \\
\hline $\begin{array}{ll}T \\
T\end{array}$ & Alta Floresta & 1 & 8 & . & 2 \\
\hline $\begin{array}{ll}T \\
\end{array}$ & D'Oeste & 0 & . & 6 & 8 \\
\hline 0 & Collder & . & 8 & 6 & 3 \\
\hline M & Juara Breves & 1 & 1 & 0 & 8 \\
\hline $\begin{array}{ll}T \\
\end{array}$ & Parintins & 5 & 7 & - & . \\
\hline
\end{tabular}

As micros, mesos e macrorregiões de influência socioeconômica dos pólos econômicos da Amazônia brasileira.

Uma vez estimados os índices de desenvolvimento socioeconômico geral, identificada a hierarquia urbana dos municípios amazônicos e estimado os movimentos migratórios entre esses municípios e os pólos econômicos, pode-se, finalmente, efetuar os cálculos do índice de interação entre dos pólos e os demais municípios para que sejam identificados quais municípios esses centros econômicos polarizam e qual a intensidade dessa polarização.

O índice de interação é, portanto, uma medida do grau de influência socioeconômica que o centro polarizador exerce sobre os demais municípios, quanto maior o índice, maior será a polarização do centro em relação ao município polarizado. Quanto maior o desenvolvimento socioeconômico das partes consideradas, quanto menor a distância e quanto maior o fluxo migratório entre elas, maior será a polarização exercida entres as áreas consideradas. Nesse 
sentido, cabe ressaltar, tanto o centro polarizador exerce influência sobre as áreas polarizadas, quanto as áreas polarizadas exercem influência sobre o centro polarizador.

O modelo proposto é, conceitualmente, o mais próximo possível da realidade, pois concebe que os municípios influenciam e são influenciados mutuamente. Alguns municípios possuem, entretanto, maior poder de influência que outros e, dentro de um sistema de redes de cidades, assumem o papel de centros de nodais, uma vez que outros municípios tendem, literalmente, a gravitar em seu entorno.

Como o índice de interação é uma medida da força de atração entre os centros dessa rede e suas áreas de influência, na caracterização das microrregiões de influência socioeconômica dos 48 pólos econômicos, adotou-se o seguinte critério para a identificação dos centros polarizadores dos municípios não-pólos: o centro polarizador de um município foi aquele que exerceu a maior força de atração e, portanto, maior poder de polarização, dado pelo valor do índice de interação entre o centro e o município, desde que respeitada a contiguidade geográfica entre os municípios polarizados por esse centro.

Efetuados todos os procedimentos necessários à regionalização da Amazônia brasileira, foram identificadas as rede microrregional de cidades dos pólos econômicos amazônicos, cuja representação espacial está ilustrada no Mapa 73. Dos 48 micropolos regionais, aquele que polarizou o maior número de municípios foi o polo de São Luiz (109), seguido pelo polo de Belém (72) e Palmas (69); por outro lado, os que polarizaram o menor número de municípios foram os pólos de Almeirim (2), Guajará-mirim (3) e Tefé (3). Tal como pode ser percebido na análise do Mapa 7.

Os mesopolos regionais são, como já comentado, pólos econômicos que polarizam, diretamente, os municípios não-pólos, bem como outros micropolos regionais e, indiretamente, os municípios polarizados por estes micropolos, dando origem, assim, à aglomerações de microrregiões, chamadas mesorregiões de influência dos mesopolos.

Dos 28 mesopolos regionais, o que polarizou, direta ou indiretamente, o maior número de municípios foi o mesopolo de São Luiz (143), seguido pelo pólo de Belém (87) e Palmas (69). Como as microrregiões são formadas pelos municípios polarizados diretamente pelos pólos regionais, fica claro que a mesorregião de São Luiz, por exemplo, é formada pelos municípios provenientes de sua microrregião de influência direta (109) mais os municípios das microrregiões de Barra do Corda (26) e Codo (8), tal como pode ser observado na comparação do Mapa 7 e o Mapa 8. 


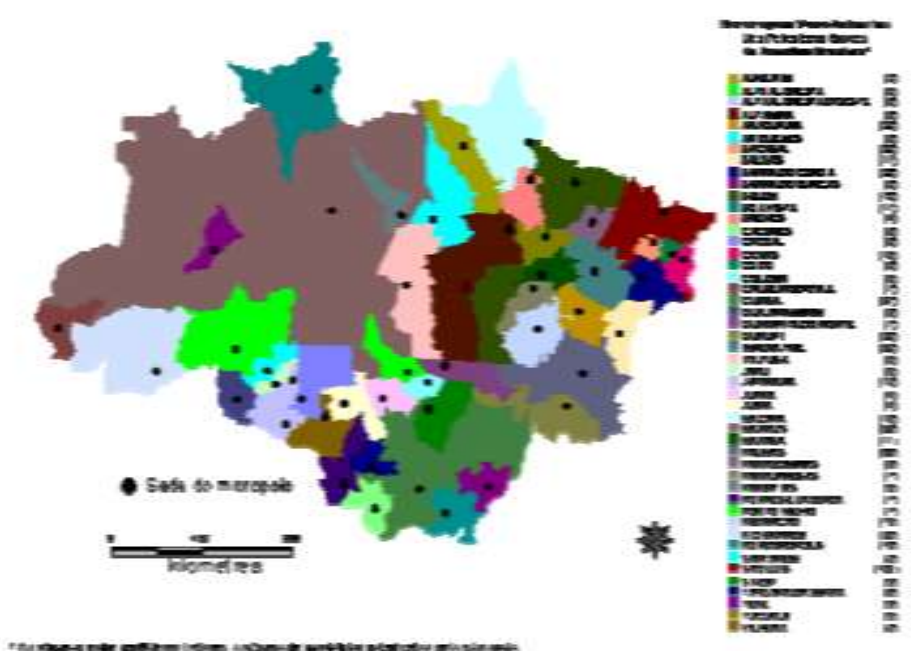

Mapa 7: AMAZÔNIA BRASILEIRA - MICRORREGIÕES SÓCIO-AMBIENTAIS DOS PÓLOS ECONÔMICOS - 2000. Fonte: IBGE: Malha digital dos municípios brasileiros - 2000 e elaboração própria.

Por fim, os macropolos regionais são pólos econômicos que polarizam, diretamente, os municípios não-pólos e outros mesopolos e, indiretamente, os micropolos polarizados por estes mesopolos, bem como os municípios polarizados por esses micropolos, dando origem, assim, grandes aglomerados de mesorregiões chamadas macrorregiões de influência dos macropolos. Como os macropolos regionais amazônicos são as próprias capitais dos estados que compõem essa região, as áreas de ilustradas no Mapa 9 refletem as áreas de influência sócio-econômica provável dessas capitais e, nesse sentido, pode-se perceber os quão diferentes são dos contornos estaduais definidos por critérios estritamente administrativos.

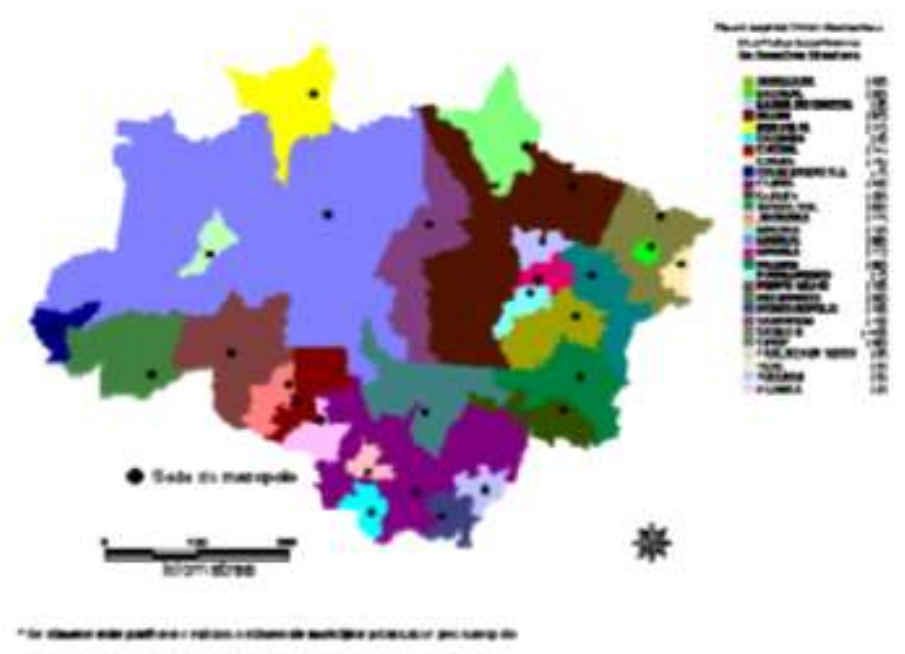

Mapa 8: AMAZÔNIA BRASILEIRA - MESORREGIÕES SÓCIO-AMBIENTAIS DOS PÓLOS ECONÔMICOS - 2000. Fonte: IBGE: Malha digital dos municípios brasileiros - 2000 e elaboração própria. 


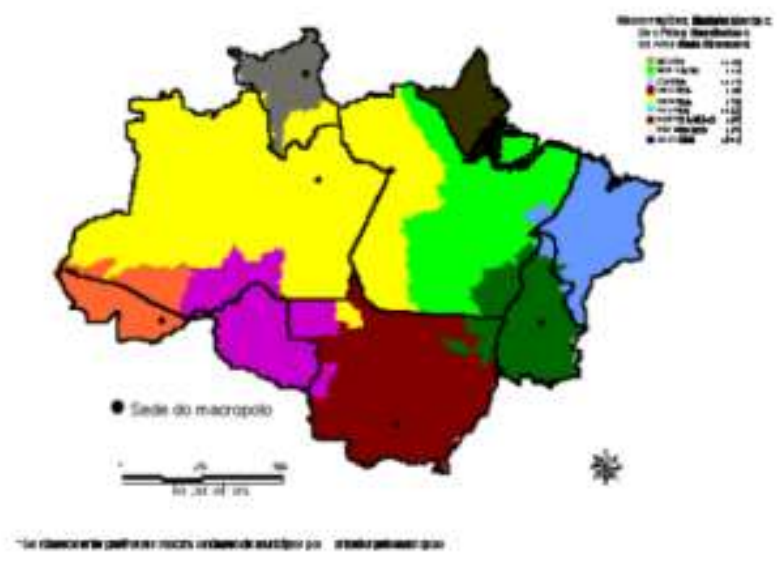

Mapa 9: AMAZÔNIA BRASILEIRA - MACRORREGIÕES SÓCIO-AMBIENTAIS DOS PÓLOS ECONÔMICOS - 2000. Fonte: IBGE: Malha digital dos municípios brasileiros - 2000 e elaboração própria.

\section{CONSIDERAÇÕESFINAIS}

O maior desafio em estabelecer um índice de desenvolvimento sócio-econômico para um potencial de degradação ambiental, como no caso específico do desflorestamento, consiste em obter medidas de um conjunto de variáveis que dêem alguma indicação do comportamento da variável dependente através de um futuro próximo. Com este fito, estoques de variáveis socioeconômicas, em um tempo t, são relacionados com dados de desflorestamento em um tempo t próximo. Nesse caso, o que se busca é, além de entender o passado, obter indicação da trajetória do fenômeno analisado, ou seja do desflorestamento, em função de conjunturas socioeconômicas. Neste caso, as taxas ou fluxos é que são modeladas em vez dos estoques. Isto implica em um mapeamento do potencial dos estoques em produzir taxas. Um maneira sugerida para isso consiste em considerar o tempo que um estoques de uma determinada conjuntura socioeconômica levam para produzir uma extensão de mudanças e usar esta relação para se calcular a velocidade ou taxa que uma certa região vai necessitar para se ajustar em termos da relação pressão/impacto.

Com este intuito, deve-se sempre buscar relacionar densidades de estoques, calculadas em função, por exemplo, da área do município, com a extensão da degradação ambiental, no caso específico a densidade de áreas desflorestadas (Fig. 10). Por conseguinte, a comparação das figuras 5 e 6 indica que, embora, em termos de degradação ambiental, o desflorestamento ainda se encontra concentrado ao longo do conhecido arco de desflorestamento (Maranhão, este do Pará, Mato Grosso, Rondônia e este do Acre) e ao longo de trechos do Rio Amazonas, há um potencial de espalhamento desse processo adentro do sul e centro do Pará, ao longo da BR-163, a qual está prestes a ser asfaltada, por todo o restante do Mato Grosso e boa parte de Rondônia. 
Desse modo, o mapa de potencial antrópica sinaliza crescentes taxas de desflorestamentos nessas regiões.

Deve-se ressaltar que a ligação quantitativa entre o complexo de dados socioeconômicos e de desflorestamento não é trivial. Não obstante, a abordagem de dimensões, obtidas por meio de classificação GoM, mostrou ser uma via acessível e de fácil leitura, sendo portanto sugerida para trabalhos que visem enfocar essa relação.

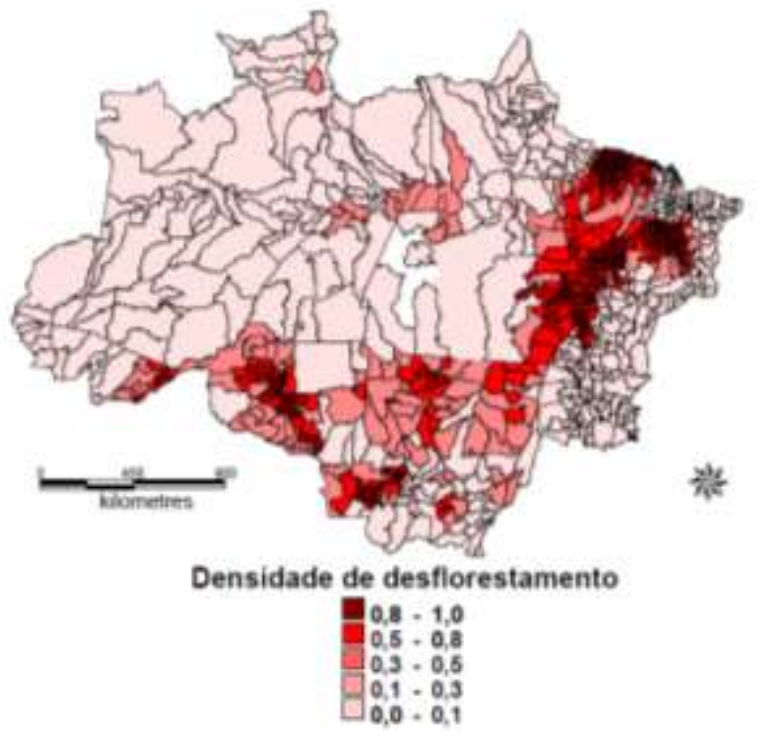

Fig. 10. Amazônia Brasileira - Densidade de áreas desflorestadas por municípios até 2001. Fonte: Malha digital dos municípios brasileiros - IBGE (2000) e INPE (2002).

A caracterização das áreas de influência socioeconômica dos pólos amazônicos traduziu, de forma bastante precisa não só a dinâmica migratória corrente, em nível macro e microrregional, como o seu mapeamento permitiu que as análises fossem efetuadas de modo a levar em conta a totalidade das configurações espaciais, evidenciando a configuração da rede de cidades, de micros e de mesorregiões que compõem a Amazônia Brasileira, obtidas através do modelo gravitacional.

Fica salientada a necessidade de que os estudos sobre os impactos ambientais incorporarem a dimensão demográfica, dando maior atenção aos deslocamentos populacionais e seus efeitos sobre a dinâmica do desenvolvimento socioeconômico regional brasileiro. Como a relação entre deslocamentos populacionais e desenvolvimento socioeconômico é especulativa, ou seja, ambas são causa e efeito do mesmo processo que as origina, acredita-se que a análise dos movimentos populacionais, no contexto dos estudos sobre economia regional, só venha a lançar luz sobre a determinação de ambos os fenômenos. 
Um outro fato digno de comentário - revelado a partir dos resultados desse estudo, que ilustra o quão ilusórias são os limites administrativos das UF nacionais no que dizem respeito às delimitações das áreas de influência socioeconômica e demográfica de seus centros econômicos diz respeito às possíveis contribuições, que ele pode vir a oferecer, às pesquisas sobre as migrações internas no Brasil, no sentido de chamar a atenção dos especialistas para que enfoquem seus trabalhos em recortes geográficos mais significativos dos que os tradicionais UF e Grandes Regiões, privilegiando escalas analíticas microrregionais.

\section{REFERÊNCIAS BIBLIOGRÁFICAS}

AJARA, Cesar. \& MOTTA, Diana M. Configuração da Rede Urbana do Brasil. Revista Paranaense de Desenvolvimento. n.100. 2001.

ANDRADE, T. A \& SERRA, R. V. Estimativas para o Produto Interno Bruto dos Municípios Brasileiros: 1975, 1980, 1985 e 1996. Rio de Janeiro: IPEA/NEMESIS, 1999. (mimeo). ANDRADE, Thompson A \& SERRA, Rodrigo V. Estimativas para o Produto Interno Bruto dos Municípios Brasileiros: 1975, 1980, 1985 e 1996. Rio de Janeiro: IPEA/NEMESIS, 1999. (mimeo). ANDRADE, Thompson A \& SERRA, Rodrigo V. O Recente Desempenho das Cidades Médias no Crescimento Populacional Urbano Brasileiro. Revista Brasileira de Estudos de População. Brasília: ABEP, v. 16, n.1/ 2, p. 7-17, jan./dez. 1999

ANDRADE, Thompson A; SANTOS, Ângela M. S. P. \& SERRA, Rodrigo V. Fluxos migratórios nas cidades médias e regiões metropolitanas Brasileiras: experiência do período 1980/96. In: ENCONTRO CHRISTALLER, Walter. Central places in southern Germany. New Jersey: Prentice-Hall, 1966. FEARNSIDE, P. M. Environmental Services as a Strategy for Sustainable Development in Rural Amazonia. Ecological Economics. 20: 53-70. 1997.

FERREIRA, Carlos Maurício de C. Espaço, Regiões e Economia Regional. In: HADDAD, Paulo R. (org.) Economia regional: teorias e métodos de análise. Fortaleza: Banco do Nordeste do Brasil S. A, 1989.

GARCIA, R. A. Modernização e Crescimento Populacional: uma aplicação da técnica grade of membership. In: SEMINÁRIO SOBRE A ECONOMIA MINEIRA, VIII, 2000, Diamantina. Anais. Belo Horizonte: CEDEPLAR/UFMG, 2000. v. 2, p. 477-492.

GARCIA, R. A.. Modernização do Nordeste Brasileiro: um estudo microrregional. In: ENCONTRO NACIONAL DE ESTUDOS POPULACIONAIS, 12, 2000a, Caxambu, MG. Brasil 500 anos: mudanças e continuidades. Belo Horizonte: ABEP, 2000. (Disponível em CDROM) Cadernos do Leste Artigos Cientificos 
GARCIA, Ricardo. Alexandrino. A migração como variável endógena: uma proposta de regionalização baseada em pólos econômicos e suas áreas de influência. 2002. 181 p. Tese (Doutorado em Demografia) - Centro de Desenvolvimento e Planejamento Regional, Universidade Federal de Minas Gerais, 2002.

INSTITUTO BRASILEIRO DE GEOGRAFIA E ESTATÍSTICA (IBGE) Censo Agropecuário de 1995/1996. (CD-ROM). Rio de Janeiro, Br: IBGE. 1996a.

INSTITUTO BRASILEIRO DE GEOGRAFIA E ESTATÍSTICA (IBGE) Censo Demográfico de 2000. (CD-ROM). Rio de Janeiro, Br: IBGE. 2000.

INSTITUTO BRASILEIRO DE GEOGRAFIA E ESTATÍSTICA (IBGE) Contagem de 1996. (CD-ROM). Rio de Janeiro, Br: IBGE. 1996b.

INSTITUTO BRASILEIRO DE GEOGRAFIA E ESTATISTICA. Banco Municipal de Informações. 2a. Ed. Rio de Janiero, IBGE, 1998. (Disponível em CD-ROM).

67

INSTITUTO BRASILEIRO DE GEOGRAFIA E ESTATISTICA. Perfil dos Municípios Brasileiros. Rio de Janiero, IBGE, 1999. (Disponível em CD-ROM).

INSTITUTO NACIONAL DE PESQUISAS ESPACIAIS (INPE) (2002) Monitoring of Brazilian Amazonian Forest by Satellite 2000 <http://www.grid.inpe.br/papers.html> (June 2002) IPEA/IBGE/NESUR (IE-UNICAMP). Pesquisas: Caracterização e Tendências da Rede Urbana do Brasil. Volumes 1 e 2. Campinas: Universidade Estadual de Campinas, 1999.

ISARD, Walter. \& BRAMAHALL, David F. Methods of regional analysis: an introduction to regional science. MIT Technology Press; New York: Wiley, 1960.

ISARD, Walter. Introduction to Regional Science. New Jersey: Prentice-Hall, 1975.

ISARD, Walter. Location and space-economy. Cambridge: MIT Press, 1956.

ISARD, Walter. Methods of regional analysis. Cambridge: MIT, 1960.

KLECKA, William R. Discriminant Analysis. 8.ed. Beverly Hills: SAGE Publications, 1980.

LEMOS, Maurício Borges. Duas Técnicas de Análise regional elaboradas a partir de categorias espaciais: a regionalização e o método estrutural - diferencial. Tese de professor titular, Instituto de Economia da Universidade Estadual de Campinas, Campinas, 1991.

LEMOS, Maurício Borges. estado e Capital: um estudo sobre a dinâmica centro X periferia. Tese de Doutorado, Instituto de Economia da Universidade Estadual de Campinas, Campinas, 1988. 
LEMOS, Mauro Borges et al. A nova geografia econômica do Brasil: uma proposta de regionalização com base nos pólos econômicos e suas áreas de influência. Belo Horizonte: CEDEPLAR, 2000. (mimeo)

LEMOS, Mauro Borges; DINIZ, Clélio Campolina; GUERRA, Leonardo Pontes;. Pólos Econômicos do Nordeste e suas Áreas de Influência: uma aplicação do modelo gravitacional utilizando Sistema de Informações Geográficas (SIG). Revista Econômica do Nordeste, 1999, $568-584$.

LOSCH, August. Economic regions. In: FRIEDMANN \& ALONSO. Regional development and planning: a reader. Cambridge: MIT, 1969

MANTON, K., WOODBURY, M., TOLLEY, D. Statistical applications using fuzzy sets. Wiley, 1994.

MONTEIRO, M.P. \& SAWYER, D. Diagnóstico demográfico, socioeconômico e de pressão antrópica na região da Amazônia Legal. In. Biodiversidade na Amazônia Brasileira (Org. Capobianco, J.P.R. et al.) São Paulo, ISA, 2001.

SAWYER, D. O. \& BELTRÃO, K. I. "Healthy Households" and Child Survival in Brazil. In: DEMOGRAPHICS AND HEALTH SURVEYS WORLD CONFERENCE (1991.

Washington). Proceedings. Columbia: IRD/Macro International, Inc., 1991, p.205-222.

THÜNEN, Johann Heinrich von. Isolated state. New York: Pergamon Press, 1966, 33-46.

VERÍSSIMO, A., ARIMA E., LIMA, E. O diagnóstico do uso da terra na Amazônia: Exploração

Madeireira, Agricultura e Agropecuária. In. Biodiversidade na Amazônia Brasileira (Org.

Capobianco, J.P.R. et al.) São Paulo, ISA, 2001.

WEBER, Alfred. Theory of the location of industries. Chicago: Chicago U.P., 1969.

ZADEH, L.A. Fuzzy sets. Informational Control, 8:338-351, 1965. 